\title{
Croatian Journal of Food Science and Technology
}

\section{TABLE OF CONTENT}

$\begin{array}{lll}\text { - } & \text { Description } & \text { p. } 1 \\ - & \text { Abstract and Indexing } & \text { p. } 1 \\ \text { - } & \text { Editorial Bord } & \text { p. } 1 \\ \text { - } & \text { Guide for Authors } & \text { p. } 3 \\ \text { - } & \text { Manuscript preparation } & \text { p. } 5\end{array}$

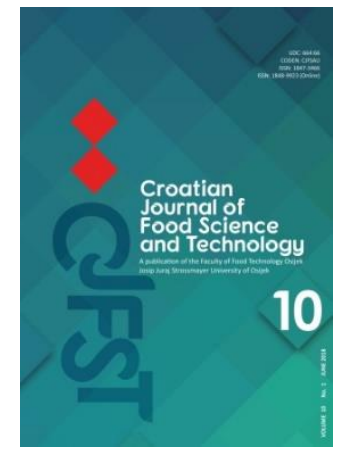

ISSN: $1847-3466$

\section{DESCRIPTION}

The Croatian Journal of Food Science and Technology is an international, blind peer-reviewed open access journal that publishes original Research papers, Preliminary communications, Scientific notes, Reviews, Professional papers and Conference papers on current topics in all areas of food science and technology. The Croatian Journal of Food Science and Technology is published by Josip Juraj Strossmayer University of Osijek, Faculty of Food Technology Osijek, Croatia.

\section{ABSTRACTING AND INDEXING}

$\begin{array}{cc}\text { CAB Abstracts database } & \text { Directory of Open Access Journals (DOAJ) } \\ \text { OpenAIRE } \\ \text { FSTA (Food Science and Technology Abstract) } \\ \text { database } & \text { Genamics JournalSeek } \\ \text { EBSCO Publishing, Inc. database } & \text { Base Biofield Academic Search Engine } \\ \begin{array}{c}\text { Portal of Croatian Scientific Journals (HRČAK) } \\ \text { Directory of Research Journals Indexing } \\ \text { Science Library Index database }\end{array} & \begin{array}{c}\text { Directory Indexing of International Research Journals } \\ \text { International Innovative Journal Impact Factor (IIJIF) } \\ \text { Google Scholar }\end{array}\end{array}$

\section{EDITORIAL BOARD}

\section{Editor-in-Chief}

Jurislav Babić, Faculty of Food Technology Osijek, Croatia

\section{Vice-Editor-in-Chief}

Maja Molnar, Faculty of Food Technology Osijek, Croatia

\section{Associate Editor}

Ante Lončarić, Faculty of Food Technology Osijek, Croatia Antonija Šarić, Faculty of Food Technology Osijek, Croatia Tihomir Kovač, Faculty of Food Technology Osijek, Croatia Marija Nujić, Faculty of Food Technology Osijek, Croatia Lahorka Budić, Faculty of Food Technology Osijek, Croatia Lidija Šoher, Faculty of Food Technology Osijek, Croatia Ivana Lauš, Faculty of Food Technology Osijek, Croatia 


\section{Croatian Journal of Food Science and Technology}

\section{Editorial Board}

Đ. Ačkar, (Faculty of Food Technology Osijek, University of Osijek, Croatia)

I. Banjari, (Faculty of Food Technology Osijek, University of Osijek, Croatia)

B. C. Behera, (Agharkar Research Institute, India)

M. Bilić, (Faculty of Food Technology Osijek, University of Osijek, Croatia)

A. Bucić-Kojić, (Faculty of Food Technology Osijek, University of Osijek, Croatia)

S. Budžaki, (Faculty of Food Technology Osijek, University of Osijek, Croatia)

D. Čačić Kenjerić (Faculty of Food Technology Osijek, University of Osijek, Croatia)

D. Gašo Sokač, (Faculty of Food Technology Osijek, University of Osijek, Croatia)

A. Gryszkin, (Wrocław University of Environmental and Life Sciences, Wroclaw, Poland)

J. Hardi, (Faculty of Food Technology Osijek, University of Osijek, Croatia)

M. Habuda-Stanić, (Faculty of Food Technology Osijek, University of Osijek, Croatia)

Z. Herceg, (Faculty of Food Technology and Biotechnology, University of Zagreb, Croatia)

D. Horvat, (Agricultural Institute Osijek, HR-31000 Osijek, Croatia)

L. Jakobek Barron, (Faculty of Food Technology Osijek, University of Osijek, Croatia)

D. Ježek, (Faculty of Food Technology and Biotechnology, University of Zagreb, Croatia)

S. Jokić, (Faculty of Food Technology Osijek, University of Osijek, Croatia)

A. Jozinović, (Faculty of Food Technology Osijek, University of Osijek, Croatia)

T. Klapec, (Faculty of Food Technology Osijek, University of Osijek, Croatia)

M. Kopjar, (Faculty of Food Technology Osijek, University of Osijek, Croatia)

D. Kovačević, (Faculty of Food Technology Osijek, University of Osijek, Croatia)

G. Krešić, (The Faculty of Tourism and Hospitality Management, Croatia)

M. Lores, (Faculty of Chemistry,Santiago de Compostela, University of Santiago de Compostela, Spain)

D. Magdić, (Faculty of Food Technology Osijek, University of Osijek, Croatia)

B. Miličević, (Faculty of Food Technology Osijek, University of Osijek, Croatia)

B. Pajin, (Faculty of Technology Novi Sad, University of Novi Sad, Serbia)

V. Piližota, (Faculty of Food Technology Osijek, University of Osijek, Croatia)

M. Planinić, (Faculty of Food Technology Osijek, University of Osijek, Croatia)

J. Pleadin, (Hrvatski veterinarski institut Zagreb, Croatia)

Lj. Primorac, (Faculty of Food Technology Osijek, University of Osijek, Croatia)

I. Strelec, (Faculty of Food Technology Osijek, University of Osijek, Croatia)

J. Šimunović, (Raleigh, North Carolina, North Carolina State University, USA)

M. Škerget, (Faculty of Chemistry and Chemical Engineering, University of Maribor, Slovenia)

D. Šubarić, (Faculty of Food Technology Osijek, University of Osijek, Croatia)

M. Tišma, (Faculty of Food Technology Osijek, University of Osijek, Croatia)

S. Tomas, (Faculty of Food Technology Osijek, University of Osijek, Croatia)

D. Velić, (Faculty of Food Technology Osijek, University of Osijek, Croatia)

S. Vidović, (Faculty of Technology Novi Sad, University of Novi Sad, Serbia)

\section{International Advisory Bord}

\author{
S. Ivanković, (Bosnia and Herzegovina) \\ H. Lelieveld, (Netherlands) \\ A. Lenart, (Poland) \\ D. B. Lund, (USA) \\ G.J. Mazza, (Canada) \\ B. McKenna, (Ireland) \\ L. Piergiovanni, (Italy)
}

\author{
G.L. Robertson, (Australia) \\ K. Sacilik, (Turkey) \\ G.M. Sapers, (USA) \\ S. Smole Možina, (Slovenia) \\ D. Tucu, (Romania) \\ V. Zambare, (USA) \\ Z. Zeković, (Serbia)
}




\section{Croatian Journal of Food Science and Technology}

\section{GUIDE FOR AUTHORS}

\section{Submission checklist}

You can use this list to carry out a final check of your submission before you send it to the journal for review. Please check the relevant section in this Guide for Authors for more details.

\section{Ensure that the following items are present:}

One author has been designated as the corresponding author with contact details:

- E-mail address

- Full postal address

- ORCID

All necessary files have been uploaded:

Manuscript:

- Include keywords

- All figures (include relevant captions)

- All tables (including titles, description, footnotes)

- Ensure all figure and table citations in the text match the files provided

Further considerations:

- Manuscript has been 'spell checked' and 'grammar checked'

- All references mentioned in the Reference List are on the proper way cited in the text, and vice versa

- Journal policies detailed in this guide have been reviewed

- Referee suggestions and contact details provided, based on journal requirements

\section{BEFORE YOU BEGIN}

\section{Ethics in publishing}

Croatian Journal of Food Science and Technology is published by the Faculty of Food Technology Osijek. Aiming to improve the overall quality of the journal, the publisher has established the following guidelines:

http://www.ptfos.unios.hr/novicjfst/index.php/ethical-guidelines-for-journal-publication/

\section{Declaration of interest}

Authors are requested to disclose any actual or potential conflict of interest including any financial, personal or other relationships with other people or organizations within three years of beginning the submitted work that could inappropriately influence, or be perceived to influence, their work. Authors must disclose any interests in Cover letter. If there are no interests to declare then please state this: 'Declarations of interest: 'none'. 


\section{Croatian Journal of Food Science and Technology}

\section{Submission declaration and verification}

Submission of an article implies that the work described has not been published previously that it is not under consideration for publication elsewhere, that its publication is approved by all authors and tacitly or explicitly by the responsible authorities where the work was carried out, and that, if accepted, it will not be published elsewhere in the same form, in English or in any other language, including electronically without the written consent of the copyright-holder. The journal will adopt procedures for detecting plagiarism in submitted items when suspicions are raised. Please note that Croatian Journal of Food Science and Technology uses Turnitin software to screen papers for unoriginal material.

\section{Contributors}

Each author is required to declare his or her individual contribution to the article: all authors must have materially participated in the research and/or article preparation, so roles for all authors should be described. The statement that all authors have approved the final article should be true and included in the disclosure.

\section{Changes to authorship}

Authors are expected to consider carefully the list and order of authors before submitting their manuscript and provide the definitive list of authors at the time of the original submission. Any addition, deletion or rearrangement of author names in the authorship list should be made only before the manuscript has been accepted and only if approved by the journal Editor. To request such a change, the Editor must receive the following from the corresponding author: (a) the reason for the change in author list and (b) written confirmation (e-mail, letter) from all authors that they agree with the addition, removal or rearrangement. In the case of addition or removal of authors, this includes confirmation from the author being added or removed.

\section{Copyright}

Upon acceptance of an article, authors will be asked to complete an 'Copyright Transfer Statement' (see more information on this). Permitted third party reuse of open access articles is determined by the author's choice of user license.

\section{Open access}

Every peer-reviewed research article appearing in this journal will be published open access. This means that the article is universally and freely accessible via the internet in perpetuity, in an easily readable format immediately after publication. The author does not have any publication charges for open access. A CC user license manages the reuse of the article. All articles will be published under the following license:

\section{Creative Commons Attribution-NonCommercial-NoDerivs (CC BY-NC-ND)}

For non-commercial purposes, lets others distribute and copy the article, and to include in a collective work (such as an anthology), as long as they credit the author(s) and provided they do not alter or modify the article.

Language (usage and editing services)

Please write your text in good English (American or British usage is accepted, but not a mixture of these). The service of proofreading is the following: 1 text card (1800 characters with spaces): 5 Euro + VAT. 


\section{Croatian Journal of Food Science and Technology}

\section{Submission}

Authors are kindly asked to read the following instructions while preparing the manuscript for publishing in the Croatian Journal of Food Science and Technology.

Manuscripts could be submitted by:

- e-mail: CJFST@ptfos.hr

- online: http://www.ptfos.unios.hr/en/index.php/manuscript-submission

\section{MANUSCRIPT PREPARATION}

\section{Peer review}

This journal operates a single blind review process. All contributions will be initially assessed by the editor for suitability for the journal. Papers deemed suitable are then typically sent to a minimum of two independent expert reviewers to assess the scientific quality of the paper. The Editor is responsible for the final decision regarding acceptance or rejection of articles.

\section{Use of word processing software}

The manuscript should be written with 1.5 spacing on one side of the paper and margins $2.5 \mathrm{~cm}$. For the text should be used normal plain font (Times New Roman, font size 12). Keep the layout of the text as simple as possible. Most formatting codes will be removed and replaced on processing the article. In particular, do not use the word processor's options to justify text or to hyphenate words. However, do use bold face, italics, subscripts, superscripts etc.

To avoid unnecessary errors you are strongly advised to use the 'spell-check' and 'grammar-check' functions of your word processor.

\section{Article structure}

Subdivision - The title of the manuscript and the title of the chapter should be short and written in bold. The title of subheading should be written in italic.

Introduction - State the objectives of the work and provide an adequate background, avoiding a detailed literature survey or a summary of the results.

Material and methods - Provide sufficient details to allow the work to be reproduced by an independent researcher. Methods that are already published should be summarized, and indicated by a reference. If quoting directly from a previously published method, use quotation marks and also cite the source. Any modifications to existing methods should also be described.

Results - Results should be clear and concise. It is preferred to write the measurement units as "kg/m".

Discussion - This should explore the significance of the results of the work, not repeat them. A combined Results and Discussion section is often appropriate. Avoid extensive citations and discussion of published literature.

Conclusions - Conclusions have to briefly explain significance of the research results. 


\section{Croatian Journal of Food Science and Technology}

\section{Essential title page information}

First page should contain concise and informative title. Under the title the manuscript must contain author/s full name/s and full family name/s, with asterisk next to the name of the corresponding author. The affiliations for all authors must be given in the following sequence: University/Institution, Faculty/Department, Postal address, City, Country. When authors have different affiliations, should be used superscripted Arabic numbers after last name of the author. Footnote at the bottom of the first page should contain information about the corresponding author (e-mail, phone, fax, address and ORCHID).

\section{Summary}

Summary must not exceed 300 words and has to show relevant data, methodology, main results and conclusion. It should not contain abbreviations or references. After summary, authors are asked to list several keywords.

\section{Keywords}

Keywords include the main topic of the paper and should not contain more than 5 words or phrases, which should be separated by commas.

\section{Tables and figures}

Please submit tables as editable text and not as images. Tables can be placed either next to the relevant text in the article, or on separate page(s) at the end. Number tables consecutively in accordance with their appearance in the text and place any table notes below the table body. Be sparing in the use of tables and ensure that the data presented in them do not duplicate results described elsewhere in the article.

Ensure that each figure has a caption. Supply captions separately, not attached to the figure. A caption should comprise a brief title (not on the figure itself) and a description of the illustration. Keep text in the illustrations themselves to a minimum but explain all symbols and abbreviations used. Be sure to use lettering, data lines, and symbols sufficiently large and thick to be clearly legible when the figure is reduced to the normal published size. Do not place figures into bordered frames. Figure caption and legend should be placed at the bottom of each figure, while table headings should appear above the tables. Preferred program for preparing figures and tables is Microsoft Office Excel.

\section{Equations}

Whenever possible formulae and equations are to be written in one line, centered on the page, and consecutively numbered in Arabic numbers between round brackets at the right margin of the paper. Refer to equations by the abbreviation "Eq.".

SI (System International) units should be used. Only symbols (not their subscripts, superscripts or description in brackets) of physical quantities should be written in italic.

\section{References}

Please ensure that every reference cited in the text is also present in the reference list (and vice versa), following the text of the manuscript. Unpublished results and personal communications are not recommended. Avoid citations in the Summary. Citation of a reference 'in press' implies that the reference has been accepted for publication.

\section{Citation in text examples}

Number of authors

At the end of the sentence As part of the sentence

Single author

Two authors

Three or more authors
(Knowles, 2007)

(Knowles and Smith, 2007)

(Knowles et al., 2007)
Knowles (2007)

Knowles and Smith (2007)

Knowles et al. (2007) 


\section{Croatian Journal of Food Science and Technology}

\section{Reference list}

Reference list which has to be written at the end of the paper, all authors have to be listed (surname and name initials - capitalizing only the initial letters) in alphabetical order, and paper of the same author by chronological order. If there are more papers from the same author published in the same year, references have to be differentiated by letters in the text $(a, b, c, d)$ behind the year of publishing. In case of multi author papers, in reference list all the authors have to be written (not the first author and mark "et al."). Also abbreviations of journals titles have to be written in italics. Abbreviations should be in accordance with the latest edition of the Thomson ISI List of Journal Abbreviations (Thomson Scientific, USA). Full stop should be used after each abbreviation.

The DOI numbers must be included in all references in manuscripts, in those that contain it (check on: http://www.crossref.org/).

For manuscripts published on the web (web references), it is necessary to write the source (the full URL should be given) and the date when the reference was last accessed and manuscript was downloaded, besides basic further information's, if known (DOI, title, author's names, dates, reference to a source publication, etc.). Web references must be included in the reference list.

\section{Reference list examples}

Journals:

Kopjar, M., Piližota, V., Hribar, J., Nedić Tiban, N., Šubarić, D., Babić, J., Požrl, T. (2008): Influence of trehalose addition on instrumental textural properties of strawberry pastes. Int. J. Food Prop. 11 (3), 646-655. https://doi.org/10.1080/10942910701584278.

\section{Books:}

Doyle, M.P., Beuchat, L.R., Montville, T.J. (2001): Food Microbiology: Fundamentals and Frontiers, Washington, USA: ASM Press, pp. 572-573.

\section{Chapter in book:}

Varoquaux, P., Wiley, R.C. (1994): Biological and Biochemical Changes in Minimally Processed Refrigerated Fruits and Vegetables. In: Minimally Processed Refrigerated Fruits and Vegetables, Wiley, R.C. (ed.), New York, USA: Chapman, pp. 226-268.

Conference proceedings:

Babić, J., Šubarić, D., Ačkar, Đ., Kopjar, M. (2008): Utjecaj hidrokoloida na reološka svojstva voštanog kukuruznog škroba. In: 43rd Croatian and 3rd International Symposium on Agriculture, Pospišil, M. (ed.), Zagreb, HR, pp. 558-562.

\section{Web references:}

Mitra Biology Resources on the Web. 2012. Histology.

http://biology.mitrasites.com/histology.html. Accessed June 4, 2012.

\section{Suggesting Reviewers}

During the submission process, authors are pre encouraged to list five names of potential reviewers with the appropriate expertise to review the manuscript. Proposed reviewers should be from different institutions to the authors; should neither be current collaborators of the co-authors nor have published with any of the co-authors of the manuscript within the last five years. The editors will not necessarily approach these referees. Please provide contact information of potential reviewers: Name and surname, institution, e-mail address. 


\section{Croatian Journal of Food Science and Technology}

\section{AFTER ACCEPTANCE}

\section{Proofs, E-Prints and Reprints}

The corresponding author will receive proofs by e-mail within 2 weeks of acceptance, which must be corrected and returned within 72 hours of receipt. Authors should carefully review and proofread the entire article for accuracy, as the Editorial Office does not participate in the proofing of articles. Once a corrected proof is published online, additional corrections cannot be made without an erratum.

The corresponding author will receive a free PDF of their own articles. Reprints may be ordered prior to publication. 